\title{
ORAL ANTIDIABETIC AGENTS IN GESTATIONAL DIABETES MELLITUS- SHIFTING OF PARADIGM?
}

\author{
AMIN MR ${ }^{1}$, HOSSAIN MZ ${ }^{1}$, MIAH MT ${ }^{1}$, YASMIN R ${ }^{1}$, CHOWDHURY MFI $^{2}$, HOQUE MA $^{2}$
}

\begin{abstract}
:
Diabetes mellitus is one of the most common medical complications of pregnancy; gestational diabetes mellitus (GDM) accounts for approximately 90-95\% of all cases. The incidence of gestational diabetes is increasing. It has been demonstrated that good metabolic control maintained throughout pregnancy can reduce maternal and fetal complications in diabetes Traditionally, insulin therapy has been considered the gold standard for management There has been a traditional reluctance to recommend oral antidiabetic drugs for the management of hyperglycaemia in gestational diabetes mellitus. The medical management of gestational diabetes is still evolving, and recent randomized controlled trials have given a glimse of hope for woman who likes to avoid insulin and prefer oral agents.

The current short acting insulin analogs lispro and aspart are safe, but there are only limited data to support the use of long acting insulin analogs. There are randomized controlled trials which have demonstrated efficacy of the oral agents glyburide and metformin. Whilst shortterm data have not demonstrated adverse effects of glyburide and metformin on the fetus, and they are increasingly being used in pregnancy, there remain long-term concerns regarding their potential for harm. This controversy related article gives an overview of the rationale for use of oral antidiabetic agents in the treatment of gestational diabetes.
\end{abstract}

J Dhaka Med Coll. 2008; 17(2) : 127-130.

\section{Discussion:}

Gestational diabetes mellitus (GDM) is defined as carbohydrate intolerance of variable severity with onset or first recognition during pregnancy. GDM has short- and long-term implications both for the mother and child. Hyperglycemia remains a major cause of maternal and fetal morbidity. Diet is the mainstay of treatment in GDM whether or not pharmacologic therapy is introduced. If patient need pharmacological management, then insulin becomes the choice of agent as it was said to be the gold standard. In a policy statement by the American Diabetes Association and the American College of Obstetricians and Gynecologists in 2004 revealed "Oral glucose lowering agents have generally not been recommended during pregnancy" ${ }^{1}$.Until the 2005 publication of the
ACHOIS trial there was a continuing argument about the value of treatment of impaired glucose tolerance or mild gestational diabetes. Conventionally, treatment has been offered in the form of dietary management with insulin added if diet alone does not achieve acceptable glycaemic levels. Oral antidiabetic agents have not been recommended generally, principally because of concerns about transplacental passage and the risk of neonatal hypoglycaemia. The statement is based on first-generation sulfonylureas (tolbutamide and chlorpropamide) which can easily cross the placenta leading to almost similar cord and maternal serum concentrations ${ }^{2}$. Early experience with these drugs included numerous cases of profound and prolonged neonatal hypoglycemia. ${ }^{3}$ Retrospective studies of series of women with type 2 diabetes mellitus

1. Assistant Professor of Medicine, Dhaka Medical College, Dhaka

2. Associate Professor of Medicine, Dhaka Medical College, Dhaka

Correspondence: Dr. Md. Robed Amin 
suggested an association between firsttrimester sulfonylurea therapy and major congenital malformations ${ }^{4,5}$

Then came the controversy issue where the Aberdeen group of Stowers and Sutherland reported successful management of gestational diabetes with oral antidiabetic agents 30 years ago but their recommendations were not taken up widely. But most centres followed the American lead of O'Sullivan from the early 1970s in which dietary management was combined with a single dose of intermediate acting insulin. The consensus about this management was challenged by the classic randomised controlled trial of Persson and colleagues in 1985. The outcomes in relation to birthweight, frequency of foetal macrosomia, newborn skinfold thicknesses and common neonatal complications, respiratory distress, hypoglycaemia, hyperbilirubinaemia and polycythaemia were not significantly different between the groups. The solitary insulin treatment with insulin was not completely successful. With so much controversy, why oral therapy still needed? Insulin therapy is associated with: 1..the fear of injections (particularly when multiple).2. the issue of compliance. 3. the risks of hypoglycemia. 4. . the increase in appetite and weight. So the next question arises is what to do? The solution is: 1 . We need oral drugs which do not cross the placenta and 2. Oral drugs which cross the placenta without causing fetal hypoglycemia, hyperinsulinemia. and teratogenic effects.

The case of Glyburide (Glibenclamide) then came into play. Using an isolated perfused human placental model, Elliott et al. demonstrated minimal placental transfer of glyburide, but greater transport of glipizide and particularly chlorpropamide and tolbutamide 6,7 . Then a comparison of glyburide and insulin in women with gestational diabetes mellitus was done ${ }^{8}$. The results of which showed there were no significant differences in mean neonatal glucose concentrations, macrosomia, neonatal intensive care unit (NICU) admission, or fetal anomalies(Table-I). Glyburide was not detected in the cord serum of any infant and only $4 \%$ of the glyburide group required insulin therapy. Of the maternal outcome variables assessed, none were significantly different between groups except the dramatic $(P$ 0.03) reduction in maternal hypoglycemic episodes in the glyburide-treated group (2\%) compared with the $20 \%$ rate for insulin. Further reports of five small retrospective reports of glyburide use for GDM have been published since $2000.9,10,11,12,13$. Summary of those studies showed results of glyburide treatment, compared with insulin: a. for the mother it is better glycemic control and less hypoglycemic episodes and b. for the fetus: lower mean glucose values (More hypoglycemia) and less chance of macrosomia. In 2005 Langer reanalyzed the results of his trial. Patients were grouped into low (less than $10 \mathrm{mg}$ ) and high (More than $10 \mathrm{mg}$ ) daily glyburide dose groups. The rate of macrosomia was 16 vs. $5 \%$ ( $P$ 0.01), respectively, in the high and low glyburide dose groups. ${ }^{14}$

Table-I

Comparison of insulin versus Insulin in Langer study

\begin{tabular}{llcc}
\hline & & \multicolumn{2}{c}{ Glyburide Insulin } \\
\cline { 3 - 4 } & & group & group \\
\hline 1. & Fetal anomaly & $2 \%$ & $2 \%$ \\
2. & Large for gestational age & $12 \%$ & $13 \%$ \\
3. & Lung complications & $8 \%$ & $6 \%$ \\
4. & Hypoglycemia & $9 \%$ & $6 \%$ \\
5. & Admission in Neonatal ICU & $6 \%$ & $7 \%$ \\
\hline
\end{tabular}

The metformin use in pregnancy was also scrutinized critically as metformin was shown to be able to significantly cross the placenta, with fetal concentrations in the range of half of maternal concentrations ${ }^{15}$. However, it does not stimulate insulin secretion or release, and does not cause hypoglycemia. Metformin enhances insulin action, stimulating glucose uptake in the liver and in the periphery and also suppressing hepatic glucose output. It is also useful in the insulin resistance syndrome and constitute an increasingly popular treatment for polycystic ovarian syndrome, often inducing ovulation and resulting in 
pregnancy. Several trials did not report any major congenital malformations in infants born to mothers who received metformin throughout pregnancy, whether those mothers were diabetics ${ }^{16,17}$ or non diabetics ${ }^{18}$. Several studies in South Africa more than 20 years ago 19,20 and in New Zealand in $2006^{21}$ reported no adverse pregnancy outcomes. The problem was that the studies were small, retrospective and non-randomised. So we need to know what are the long term effects of exposing the fetus to metformin?. The largest trial of metformin against insulin, popularly known as MiG study is completed and the results of which are published. ${ }^{22}$. It would therefore seem that there is a place for the use of metformin in the management of gestational diabetes. The loss of weight from enrolment to the postpartum visit was $8.1 \pm 5.1 \mathrm{~kg}$ in the metformin group and $6.9 \pm 5.3 \mathrm{~kg}$ in the insulin group and this difference is highly significant $\mathrm{p}<0.006$. Metformin reduces pregnancy-associated weight gain compared with the alternatives. There was no excess of neonatal hypoglycaemia in the metformin group or of respiratory distress syndrome, birth trauma, or low Apgar scores. There were no significant differences in rates of birthweight below the tenth or abovethe 90th centile or in any of the neonatal anthropometry measurements. Cord blood serum insulin concentrations were slightly higher at $50 \mathrm{pmol} / \mathrm{L}$ in the metformin group versus $40 \mathrm{pmol} / \mathrm{L}$ in the insulin group but this difference was not significant. A MEDLINE search (1966-March 2007) showed

oral antidiabetic agents in pregnancy and lactation is on way of paradigm shift ${ }^{23}$. It showed neither glyburide nor metformin has caused developmental toxicity in humans. Glyburide has been used for the treatment of gestational diabetes, and metformin has been used in women with PCOS who eventually became pregnant.

The available data suggest that glyburide and metformin are not teratogenic in humans when used in clinically recommended doses. The data also suggest that glyburide may be sed for the treatment of gestational diabetes in some women, while metformin may be used safely for ovulation in women with PCOS. Metformin, glyburide, and glipizide appear to be compatible with breast-feeding. Randomized controlled trials will better elucidate the benefit of glyburide, metformin, and thiazolidinediones in pregnancy and over the long-term. Such data on the use of OAAs in pregnancy are shifting the paradigm that once stated that they should never be used in pregnancy. This shift may be welcome to women with gestational diabetes who are inconvenienced by injections and to those in areas where insulin may not be readily available or is cost prohibitive. With the growing rates of diabetes, especially in the developing world, such a shift in paradigm may be greatly appreciated

\section{Conclusion:}

There is evidence that good results can be achieved with OHAs providing that euglycemia targets are achieved. The ease of education and management of these selected pregnant diabetic patients make the use of OHAs an attractive option, especially in a poorly resourced environment. But there are notable limitations to the current literature. First, there are possible publication bias. Though published and unpublished studies show no differences between groups-this is due to small groups included in the studies.

Large group studies are needed to delineate the real picture.

\section{Referrences:}

1. American Diabetes Association: Gestational diabetes mellitus. Diabetes Care. 2004; 27 (Suppl. 1): S88 -S90

2. Stowers JM, Sutherland HW. The use of sulphonylureas biguanides and insulin in pregnancy. In: Sutherland HW, Stowers JM, eds. Carbohydrate metabolism in pregnancy and the newborn. Edinburgh, Churchill Livingstone. 1975: 205-20.

3. Zucker P, Simon G. Prolonged symptomatic neonatal hypoglycemia associated with maternal chlorpropamide therapy. Pediatrics. 1968; 42: 824-825.

4. Piacquadio K, Hollingsworth DR, Murphy H. Effects of in-utero exposure to oral hypoglycaemic drugs. Lancet. 1991;338:866-869.

5. Schaefer-Graf UM, Buchanan TA, Xiang A, Songster G, Montoro M, Kjos SL. Patterns of congenital anomalies and relationship to initial 
maternal fasting glucose levels in pregnancies complicated by type 2 and gestational diabetes. Am J Obstet Gynecol. 2000;182:313-320

6. Elliott BD, Langer O, Schenker S, Johnson RF: Insignificant transfer of glyburide occurs across the human placenta. Am J Obstet Gynecol. 1991; 165: 807-812,.

7. Elliott BD, Langer O, Schenker S, Johnson RF, Prihoda T: Comparative placental transport of oral hypoglycemic agents in humans: a model of human placental drug transfer. Am J Obstet Gynecol . 1994; 171: 653-660

8. Oded Langer O, Conway DI, Michael Berkus, Xenakis EM. Andolga Gonzales A. R.N. N Engl J Med. 2000; 343: 1134-1138.

9. Jacobson GF, Ramos GA, Ching JY, Kirby RS, Ferrara A, Field DR: Comparison of glyburide and insulin for the management of gestational diabetes in a large managed care organization. Am J Obstet Gynecol. 2005, 193:118-124.

10. Conway DL, Gonzales O, Skiver D: Use of glyburide for the treatment of gestational diabetes: the San Antonio experience. J Matern Fetal Neonat Med. 2004; 15: 51-55.

11. Kremer CJ, Duff P: Glyburide for the treatment of gestational diabetes. Am J Obstet Gynecol. 2004; 190: $1438-1439$.

12. Chmait R, Dinise $\mathrm{T}$, Moore $\mathrm{T}$ : Prospective observational study to establish predictors of glyburide success in women with gestational diabetes mellitus. J Perinatol. 2004; 24: 617-622.

13. Fines VL, Moore TR, Castle S: Comparison of Glyburide and Insulin Treatment in Gestational Diabetes Mellitus on Infant Birth Weight and Adiposity. Society for Maternal-Fetal Medicine Annual Meeting 2004, New Orleans, LA, USA.
14. Langer O, Yogev Y, Xenakis EM, Rosenn B: Insulin and glyburide therapy: dosage, severity level of gestational diabetes, and pregnancy outcome. Am J Obstet Gynecol. 2005, 192:134139

15. Hague WM, et al: Metformin crosses the placenta: a modulator for fetal insulin resistance? (Letter) BMJ. 4 December 2003.

16. 1- Reece EA, Homko CJ. Metformin in pregnancy: Ready or not. Curr Opin Endocrinol Diabetes 2006;13:185-190.

17. Coetzee EJ, Jackson WP. Metformin in management of pregnant insulin-dependent diabetics. Diabetologia 1979;16: 241.

18. Glueck CJ, et al. Continuing metformin throughout pregnancy in women with polycystic ovary syndrome appears to safely reduce first trimester spontaneous abortion: a pilot study. Fertil Steril 2001;75:46-52.

19. Coetzee EJ, Jackson WP: Pregnancy in established non-insulin-dependent diabetics. S Afr Med J. 1980, 58: 795- 802.

20 Coetzee EJ, Jackson WP: The management of noninsulin-dependent diabetes during pregnancy. Diabetes Res. 1986; 1: 281-287.

21. Hughes R, Rowan J. Pregnancy in women with type 2 diabetes: who takes metformin and what is the outcome? Diabet Med. 2006; 23: 318-322.

22. Rowan JA, Hague WM, Gao W, Battin MR, Moore MP. Metformin versus insulin for the treatment of gestational diabetes. N Engl J Med 2008; 358: 2003-15.

23. Denice S Feig, Gerald G Briggs, Gideon Koren, Ann Pharmacother. 2007; 41(7): 1174-1180. 